\title{
High-pressure processing decelerates lipolysis and formation of volatile compounds in ovine milk blue-veined cheese
}

\author{
J. Calzada, A. Del Olmo, A. Picon, P. Gaya, and M. Nuñez ${ }^{1}$ \\ Departamento de Tecnología de Alimentos, Instituto Nacional de Investigación y Tecnología Agraria y Alimentaria (INIA), 28040 Madrid, Spain
}

\begin{abstract}
Enzyme-rich cheeses are prone to over-ripening during refrigerated storage. Blue-veined cheeses fall within this category because of the profuse growth of Penicillium roqueforti in their interior, which results in the production of highly active proteinases, lipases, and other enzymes responsible for the formation of a great number of flavor compounds. To control the excessive formation of free fatty acids (FFA) and volatile compounds, blue-veined cheeses were submitted to high-pressure processing (HPP) at 400 or $600 \mathrm{MPa}$ on d 21, 42, or 63 after manufacture. Cheeses were ripened for $30 \mathrm{~d}$ at $10^{\circ} \mathrm{C}$ and $93 \%$ relative humidity, followed by $60 \mathrm{~d}$ at $5^{\circ} \mathrm{C}$, and then held at $3^{\circ} \mathrm{C}$ until d 360. High-pressure processing influenced the concentrations of acetic acid and short-chain, medium-chain, and long-chain FFA. The effect was dependent on treatment conditions (pressure level and cheese age at the time of treatment). The lowest concentrations of acetic acid and FFA were recorded for cheeses treated at $600 \mathrm{MPa}$ on d 21; these cheeses showed the lowest esterase activity values. Acetic acid and all FFA groups increased during ripening and refrigerated storage. The 102 volatile compounds detected in cheese belonged to 10 chemical groups (5 aldehydes, 12 ketones, 17 alcohols, 12 acids, 35 esters, 9 hydrocarbons, 5 aromatic compounds, 3 nitrogen compounds, 3 terpenes, and 1 sulfur compound). High-pressure processing influenced the levels of 97 individual compounds, whereas 68 individual compounds varied during refrigerated storage. Total concentrations of all groups of volatile compounds were influenced by HPP, but only ketones, acids, esters, and sulfur compounds varied during refrigerated storage. The lowest total concentrations for most groups of volatile compounds were recorded for the cheese pressurized at $600 \mathrm{MPa}$ on $\mathrm{d} 21$. A principal component analysis combining total concentrations of groups of FFA and volatile compounds discriminated cheeses by age and by the pressure level applied to HPP cheeses.
\end{abstract}

Received July 2, 2013.

Accepted September 5, 2013.

${ }^{1}$ Corresponding author: nunez@inia.es
Key words: high-pressure processing, lipolysis, volatile compound, blue-veined cheese

\section{INTRODUCTION}

Flavor, rheological properties, and visual appearance determine cheese quality (Fox and Wallace, 1997). Cheese flavor, probably the main trait influencing its quality, is caused by the interaction of many compounds responsible for taste and aroma. These compounds are produced during manufacture and ripening through the metabolism of lactose, lactate, and citrate, the liberation of FFA, and the degradation of caseins to peptides and free amino acids (McSweeney and Sousa, 2000; Collins et al., 2003). Primary degradation is followed by the secondary catabolism of the resulting products to compounds that, in many cases, have higher flavor impact than their respective precursors. More than 600 volatile compounds have been identified in cheese, most of which have been associated with particular odor and aroma notes (Molimard and Spinnler, 1996; Curioni and Bosset, 2002).

Coagulant enzymes, together with lactic starter cultures and their enzymes, are responsible for the biochemical changes occurring during the manufacture and ripening of semihard and hard cheeses made from pasteurized milk, because most of the microorganisms and enzymes present in raw milk have been inactivated by the thermal treatment. In the case of blue-veined cheeses, Penicillium roqueforti is an additional major ripening agent responsible for their unique flavor. Penicillium roqueforti consumes lactic acid, causing an increase in cheese $\mathrm{pH}$ value favorable for many chemical reactions, produces extracellular proteinases and lipases (Gripon et al., 1977; Lamberet and Menassa, 1983), and has the ability to form methyl ketones through the $\beta$-oxidation of FFA followed by a decarboxylation reaction (Kinsella and Hwang, 1976).

The activity of enzymes and microorganisms persists during the refrigerated storage of ripe cheese at distribution and retail, which can cause over-ripening if levels of flavor compounds above the desired balanced concentrations for a particular cheese variety are attained. Thus, the cheese purchased by the con- 
sumer may have a stronger or different flavor than the manufacturer intended (Wick et al., 2004). Blue-veined cheeses, because of their richness in enzymatic activities, seem particularly prone to over-ripening defects during the refrigerated storage of ripe cheese. An approach to prevent over-ripening and prolong the shelf life of ripe cheese is frozen storage. Although cheese flavor remains unchanged at thawing, both texture and visual appearance are negatively affected by freezing (Tejada et al., 2000; Van Hekken et al., 2005).

High-pressure processing (HPP), with a negligible effect on flavor characteristics, meets the increasing consumer demand for fresh-tasting, minimally processed foods. It has been successfully applied to milk and cheese for the inactivation of pathogenic and spoilage microorganisms (O'Reilly et al., 2000; Arqués et al., 2006). In addition, HPP may be a useful tool for the inactivation of enzymes present in cheese such as proteinases (García-Risco et al., 2003; Huppertz et al., 2004), peptidases (Malone et al., 2003; Juan et al., 2007), and esterases (Ávila et al., 2007). The formation of volatile compounds in cheese is also influenced by HPP, at a variable degree that depends on the pressure level applied and the age of cheese at the time of treatment (Ávila et al., 2006; Arqués et al., 2007). Consequently, HPP seems a feasible procedure to prevent over-ripening during the refrigerated storage of blue-veined cheese.

In a previous study, we reported the effect of HPP on the proteolysis and formation of biogenic amines in blue-veined cheese made from ovine milk (Calzada et al., 2013). However, the effects of HPP on the lipolysis and formation of volatile compounds in blue-veined cheese are not well known. In the only work published on the subject (Voigt et al., 2010), the authors did not find significant differences in the concentrations of FFA and methyl ketones when comparing pressurized and control blue-veined cheeses, a result that could be ascribed to the short refrigerated storage period of cheeses after HPP (only $28 \mathrm{~d}$ ). In the present work, we investigated the influence of HPP applied to ovine milk blue-veined cheese at 400 or $600 \mathrm{MPa}$ on d 21, 42, or 63 after manufacture on the lipolysis and formation of volatile compounds during a 90-d ripening period and a further $270-d$ refrigerated storage period.

\section{MATERIALS AND METHODS}

\section{Cheese Manufacture and HPP}

The manufacturing procedure of blue-veined cheese from pasteurized ovine milk was described in a previous work (Calzada et al., 2013). Two batches of blue-veined cheese were made on consecutive days, each from 1,200
L of milk inoculated with lactic cultures and $P$. roqueforti. Cheeses, $18 \mathrm{~cm}$ in diameter and $10 \mathrm{~cm}$ high, were ripened at $10^{\circ} \mathrm{C}$ and $93 \%$ relative humidity until d 30 and then at $5^{\circ} \mathrm{C}$ from d 30 to d 90 . After $90 \mathrm{~d}$, they were held at $3^{\circ} \mathrm{C}$ until d 360 .

Cheeses were pressurized at 400 or $600 \mathrm{MPa}$ for 5 min, after 21, 42, or $63 \mathrm{~d}$ of ripening, as described by Calzada et al. (2013). Treatments were coded as 400W3, 600W3, 400W6, 600W6, 400W9, and 600W9 according to the pressure level applied (400 or $600 \mathrm{MPa})$ and the age of cheese $(3,6$, or $9 \mathrm{wk})$ at pressurization. Cheeses were unpackaged after HPP, and ripening and storage proceeded under the same conditions as for control cheese.

A different cheese per treatment (1 control and 6 HPP) was sampled at each of the times of analysis. Two 100-g pieces per cheese were wrapped in aluminum foil, vacuum-packaged, and frozen at $-40^{\circ} \mathrm{C}$ for chemical analyses.

\section{FFA Determination}

Acetic acid, propionic acid, and FFA from butyric $\left(\mathrm{C}_{4: 0}\right)$ to linolenic acid $\left(\mathrm{C}_{18: 3}\right)$ in cheese were determined by gas chromatography with flame-ionization detection, as described by Fernández-García et al. (2006), with elution in $8 \mathrm{~mL}$ of diethyl ether containing $2 \%$ formic acid. Frozen cheese pieces were thawed overnight at $4^{\circ} \mathrm{C}$ before analysis. At all sampling times, acids were extracted from cheeses using a solid-phase extraction technique, with pentanoic, nonanoic, and heptadecanoic acids added as internal standards. A Hewlett-Packard 6890 gas chromatograph (Agilent Technologies, Las Rozas, Spain) equipped with an automatic sampler (HP 7683), a split/splitless injector, a FFAP column (Agilent Technologies, $30 \mathrm{~m} \times 0.32 \mathrm{~mm}$ i.d. $\times 0.25 \mu \mathrm{m}$ film thickness) and a flame-ionization detector was used for the analysis. Injection ( $1 \mu \mathrm{L}$ of sample) was performed in split mode at $1: 20$ split ratio, at $260^{\circ} \mathrm{C}$. Helium was the carrier gas, with the flow set for maintaining a constant pressure of $0.80 \mathrm{~kg} / \mathrm{cm}^{2}$. For chromatographic separation, the temperature was increased from 65 to $240^{\circ} \mathrm{C}$ at a rate of $10^{\circ} \mathrm{C} / \mathrm{min}$, and held at $240^{\circ} \mathrm{C}$ for 12.5 min. Fifteen standard solutions of FA were used for the calculation of calibration curves. Individual FFA were separated, identified, and quantified, and their concentrations expressed in milligrams per gram of cheese DM.

\section{Determination of Esterase Activity}

Esterase activity was determined in duplicate on cheese extracts according to the method described by Ávila et al. (2007) with some modifications. Ten grams 
of cheese was homogenized with $20 \mathrm{~mL}$ of phosphate buffer (0.1 $M, \mathrm{pH} 7.0)$ in an Ultra-Turrax T8 homogenizer (IKA Labortechnik, Staufen, Germany), followed by centrifugation at $10,000 \times g$ for $20 \mathrm{~min}$ at $4^{\circ} \mathrm{C}$ and filtering through Whatman No. 2 paper (Whatman International Ltd., Maidstone, UK). The chromogenic substrate was $\alpha$-naphthylbutyrate (Sigma-Aldrich, Steinhem, Germany). The assay mixture contained 30 $\mu \mathrm{L}$ of chromogenic substrate, $600 \mu \mathrm{L}$ of distilled water, and different volumes $(100,200$, or $400 \mu \mathrm{L})$ of cheese homogenate and phosphate buffer $(0.1 \mathrm{M}, \mathrm{pH} 7.5)$ to a final volume of $1,230 \mu \mathrm{L}$. The assay mixture was incubated for $1 \mathrm{~h}$ at $37^{\circ} \mathrm{C}$ in a water bath and centrifuged at $12,000 \times g$ for $5 \mathrm{~min}$ at room temperature. Finally, 900 $\mu \mathrm{L}$ of supernatant was mixed with $150 \mu \mathrm{L}$ of Fast Red TR salt (Sigma-Aldrich) aqueous solution $(2.7 \mathrm{mg} /$ $\mathrm{mL}$ ). After $5 \mathrm{~min}$ at room temperature, the absorbance was measured at $537 \mathrm{~nm}$ using a DU650 spectrophotometer (Beckman Coulter Inc., Brea, CA). Esterase activity was calculated from absorbance values in the range of 0.1 to 0.9 by means of a $\alpha$-naphthol standard curve. One unit of enzymatic activity was defined as the amount of enzyme that liberated 1 pmol of $\alpha$-naphthol per minute and gram of cheese at $37^{\circ} \mathrm{C}$ and $\mathrm{pH} 7.5$.

\section{Determination of Volatile Compounds}

Volatile compounds were extracted from cheese using a solid-phase microextraction method (Mallia et al., 2005). Five grams of cheese was homogenized in a mechanical grinder with $35 \mathrm{~g}$ of $\mathrm{Na}_{2} \mathrm{SO}_{4}$ and $100 \mu \mathrm{L}$ of an aqueous solution of $1,058 \mathrm{mg} / \mathrm{L}$ cyclohexanone as internal standard. Two grams of the mixture was weighed in a $15-\mathrm{mL}$ headspace glass vial sealed with a polytetrafluoroethylene (PTFE)-faced silicone septum (Supelco, Bellefonte, PA). Vials were submerged in a thermostat-controlled bath at $30^{\circ} \mathrm{C}(\mathrm{D} 3$ model, Haake, Berlin, Germany) for both equilibration (20 min) and extraction (30 min) phases. A solid-phase microextraction manual holder equipped with a $75-\mu \mathrm{m}$ StableFlex carboxen/polydimethylsiloxane (CAR/PDMS) coated fiber (Supelco) was inserted through the PTFE septum for headspace extraction, after which it was inserted into the GC injection port for desorption $\left(270^{\circ} \mathrm{C} / 10\right.$ min in splitless mode). Before use, the fiber was conditioned in the injection port of the $\mathrm{GC}\left(300^{\circ} \mathrm{C} / 1 \mathrm{~h}\right)$ as recommended by manufacturer. After each run, the fiber was cleaned up to avoid carryover problems and, periodically, fiber sensitivity was tested with an aqueous solution of the internal standard. All analyses were run using the same fiber unit.

Chromatography (GC-MS) was carried out in a capillary column (60 m long, $0.25 \mathrm{~mm}$ i.d., $0.5 \mu \mathrm{m}$ film thickness; Zebron-WAX plus, Phenomenex, Torrance,
CA), with helium flow at $1.4 \mathrm{~mL} / \mathrm{min}$ for $1 \mathrm{~min}$ followed by $1 \mathrm{~mL} / \mathrm{min}$, and the following temperature program: $7 \mathrm{~min}$ at $40^{\circ} \mathrm{C}$, first ramp $2^{\circ} \mathrm{C} / \mathrm{min}$ to $90^{\circ} \mathrm{C}$, second $\operatorname{ramp} 3^{\circ} \mathrm{C} / \mathrm{min}$ to $150^{\circ} \mathrm{C}$, final ramp $9^{\circ} \mathrm{C} / \mathrm{min}$ to $240^{\circ} \mathrm{C}$, and $8 \mathrm{~min}$ at $240^{\circ} \mathrm{C}$. Detection was performed with electron impact ionization, with $70 \mathrm{eV}$ ionization energy operating in the full-scan mode at 1.74 scans/s. Source and quadrupole temperatures were 230 and $150^{\circ} \mathrm{C}$, respectively. Compound identification was carried out by injection of commercial standards and by spectra comparison using the Wiley7Nist05 Library (Wiley and Sons Inc., Weinheim, Germany). The sum of abundances of characteristic ions was used for semiquantitation of compounds. The relative abundances of volatile compounds were calculated by multiplying the respective peak areas by $10^{3}$ and dividing by the cyclohexanone peak area..

\section{Statistical Treatment}

Data obtained were analyzed by a 2-way ANOVA, with treatment (6 HPP treatments and control) and cheese age as the main effects. Means were compared using Tukey's test, with significance declared at $P \leq$ 0.05. Principal component analysis was carried out on the total concentrations of groups of FFA and volatile compounds of 180-d and 360-d cheeses for the discrimination of samples according to treatment and cheese age. The SPSS Win 14.0 software (SPSS Inc., Chicago, IL) was used for the statistical analysis of data.

\section{RESULTS AND DISCUSSION}

\section{Acetic and Propionic Acids}

Acetic acid derives mostly from metabolism of lactose, lactate, and citrate by lactic acid bacteria and other microorganisms (McSweeney and Sousa, 2000). Both treatment and cheese age significantly influenced $(P<0.001)$ the concentration of acetic acid in blueveined ovine milk cheese (Table 1 ). In control cheese, it increased during ripening from $1.11 \mathrm{mg} / \mathrm{g}$ of $\mathrm{DM}$ on d 1 to $1.62 \mathrm{mg} / \mathrm{g}$ of $\mathrm{DM}$ on d 90, and afterward declined slightly during refrigerated storage, to $1.39 \mathrm{mg} / \mathrm{g}$ of DM on d 360 (Table 2). High-pressure processing of cheeses on d 21 arrested the production of acetic acid, independently of the pressure level applied, more markedly than in cheeses pressurized on d 42 or d 63 . At the end of ripening, the 400W3 and 600W3 cheeses showed the lowest concentrations of acetic acid, differences that persisted until d 360. Acetic acid, a major odorant of Cheddar, Gruyère, and Emmental cheeses (Curioni and Bosset, 2002), plays an important role in cheese flavor and aroma by itself and as a substrate for 
Table 1. Levels of significance of the ANOVA main effects highpressure processing (HPP) treatment and cheese age $(\mathrm{T})$, and their interaction $(\mathrm{HPP} \times \mathrm{T})$, on the total concentrations of the main groups of carboxylic acids and volatile compounds in ovine milk blue-veined cheeses

\begin{tabular}{lccc}
\hline & \multicolumn{3}{c}{ Factor } \\
\cline { 2 - 4 } Chemical compound & $\mathrm{HPP}$ & $\mathrm{T}$ & $\mathrm{HPP} \times \mathrm{T}$ \\
\hline or group & $* * *$ & $* * *$ & $* * *$ \\
Acetic acid & $* * *$ & $* * *$ & $* *$ \\
Short-chain FFA & $* * *$ & $* * *$ & $* * *$ \\
Medium-chain FFA & $* * *$ & $* * *$ & $* * *$ \\
Long-chain FFA & $* * *$ & $\mathrm{NS}$ & $* * *$ \\
Aldehydes & $* * *$ & $* * *$ & $* * *$ \\
Ketones & $* * *$ & $\mathrm{NS}$ & $\mathrm{NS}$ \\
Alcohols & $* * *$ & $* * *$ & $*$ \\
Acids & $* * *$ & $* *$ & $* *$ \\
Esters & $* * *$ & $\mathrm{NS}$ & $\mathrm{NS}$ \\
Hydrocarbons & $* * *$ & $\mathrm{NS}$ & $\mathrm{NS}$ \\
Aromatic compounds & $* * *$ & $\mathrm{NS}$ & $*$ \\
Nitrogen compounds & $* * *$ & $\mathrm{NS}$ & $\mathrm{NS}$ \\
Terpenes & $*$ & $* *$ & $\mathrm{NS}$ \\
Sulfur compounds & & &
\end{tabular}

*** $P<0.001 ; * * P<0.01 ; * P<0.05$.

ester formation through esterification reactions. In the present work, the decline in acetic acid concentration generally observed during refrigerated storage may be ascribed to ester formation.

Propionic acid was found at low concentrations, ranging from 0.01 to $0.03 \mathrm{mg} / \mathrm{g}$ of cheese DM (data not shown), during ripening and refrigerated storage of control and HPP cheeses, without a clear influence of treatment or cheese age. Propionic acid, mainly formed by lactate-metabolizing microorganisms, is characteristic of Swiss-type cheeses and has also been detected in Cheddar and Camembert cheeses (Curioni and Bosset, 2002). Within blue-veined varieties, its presence has been reported only in Gorgonzola cheese, at low concentrations that accounted for 0.4 to $0.6 \%$ of total carboxylic acids (Moio et al., 2000).

Branched-chain carboxylic acids, deriving from the metabolism of leucine, isoleucine, and valine (Yvon and Rijnen, 2001), were not detected in control or HPP cheeses. These compounds have been found in many cheese varieties (Curioni and Bosset, 2002), including Gorgonzola cheese, in which they represented up to $4.4 \%$ of total carboxylic acids (Moio et al., 2000). Branched-chain carboxylic acids may be formed by certain strains of lactic acid bacteria and gram-negative bacteria such as Pseudomonas spp. (Morales et al., 2005). The high microbiological quality of the cheeses studied in the present work, with contaminating bacteria at very low levels (Calzada et al., 2013), probably impeded the formation of these compounds.

\section{Free Fatty Acids}

Short-chain ( $\mathbf{S C}, \mathrm{C}_{4: 0}$ to $\mathrm{C}_{8: 0}$ ) FFA originate from esterase- or lipase-mediated hydrolysis of triacylglycerides, but also from the fermentation of lactose and lactate, from the degradation of amino acids, and from the oxidation of some ketones, esters, and aldehydes (Molimard and Spinnler, 1996; Collins et al., 2003). In the present work, the formation of SC FFA was significantly $(P<0.001)$ influenced by treatment and cheese age (Table 1). Total SC FFA concentration increased 51.7 -fold during ripening of control cheese from d 1 to 90, and 2.9-fold during refrigerated storage until d 360 (Table 2). The respective levels of individual SC FFA $\mathrm{C}_{4: 0}, \mathrm{C}_{6: 0}$, and $\mathrm{C}_{8: 0}$ were $1.32,0.85$, and $0.93 \mathrm{mg} / \mathrm{g}$ of $\mathrm{DM}$ on $\mathrm{d} 90$, and reached $2.94,2.39$, and $3.56 \mathrm{mg} / \mathrm{g}$ of $\mathrm{DM}$ on $\mathrm{d} 360$.

Table 2. Concentrations of acetic acid and short-chain free fatty acids (SC FFA) during ripening and refrigerated storage of ovine milk blueveined control and high-pressure processed (HPP) cheeses pressurized at 400 or $600 \mathrm{MPa}$ after 3, 6, or 9 wk (W3, W6, W9) of ripening ${ }^{1}$

\begin{tabular}{|c|c|c|c|c|c|c|c|c|}
\hline $\begin{array}{l}\text { Chemical compound } \\
\text { or group }\end{array}$ & Day & Control & 400W3 & 600W3 & 400W6 & 600W6 & 400W9 & 600W9 \\
\hline \multirow[t]{5}{*}{ Acetic acid } & 1 & $1.11 \pm 0.03$ & & & & & & \\
\hline & 21 & $0.63 \pm 0.10^{\mathrm{b}}$ & $0.45 \pm 0.08^{b}$ & $0.19 \pm 0.02^{\mathrm{a}}$ & & & & \\
\hline & 63 & $1.72 \pm 0.21^{\mathrm{d}}$ & $0.61 \pm 0.07^{\mathrm{ab}}$ & $0.39 \pm 0.02^{\mathrm{a}}$ & $1.08 \pm 0.13^{\mathrm{bc}}$ & $0.75 \pm 0.08^{\mathrm{abc}}$ & $1.21 \pm 0.11^{\mathrm{bcd}}$ & $1.35 \pm 0.10^{\mathrm{cd}}$ \\
\hline & 90 & $1.62 \pm 0.15^{\mathrm{c}}$ & $0.50 \pm 0.06^{\mathrm{a}}$ & $0.44 \pm 0.07^{\mathrm{a}}$ & $1.72 \pm 0.18^{\mathrm{c}}$ & $1.20 \pm 0.14^{\mathrm{bc}}$ & $1.51 \pm 0.23^{\mathrm{c}}$ & $0.79 \pm 0.12^{\mathrm{ab}}$ \\
\hline & 180 & $1.67 \pm 0.12^{\mathrm{d}}$ & $0.46 \pm 0.01^{\mathrm{ab}}$ & $0.39 \pm 0.02^{\mathrm{a}}$ & $1.33 \pm 0.03^{\mathrm{cd}}$ & $0.87 \pm 0.12^{\mathrm{bc}}$ & $0.92 \pm 0.10^{\mathrm{bc}}$ & $0.68 \pm 0.09^{\mathrm{ab}}$ \\
\hline \multirow[t]{7}{*}{ SC FFA $\left(\mathrm{C}_{4: 0}-\mathrm{C}_{8: 0}\right)$} & 1 & $0.06 \pm 0.01$ & & & & & & \\
\hline & 21 & $0.72 \pm 0.15^{\mathrm{b}}$ & $0.74 \pm 0.11^{\mathrm{b}}$ & $0.19 \pm 0.08^{\mathrm{a}}$ & & & & \\
\hline & 42 & $2.82 \pm 0.38^{\mathrm{bc}}$ & $0.82 \pm 0.16^{\mathrm{a}}$ & $0.34 \pm 0.10^{\mathrm{a}}$ & $3.25 \pm 0.22^{\mathrm{c}}$ & $2.47 \pm 0.39^{\mathrm{b}}$ & & \\
\hline & 63 & $2.37 \pm 0.20^{\mathrm{b}}$ & $0.91 \pm 0.19^{\mathrm{a}}$ & $0.88 \pm 0.21^{\mathrm{a}}$ & $3.95 \pm 0.36^{\mathrm{c}}$ & $3.50 \pm 0.42^{\mathrm{bc}}$ & $3.81 \pm 0.16^{\mathrm{c}}$ & $2.25 \pm 0.25^{\mathrm{ab}}$ \\
\hline & 90 & $3.10 \pm 0.33^{\mathrm{ab}}$ & $1.44 \pm 0.10^{\mathrm{a}}$ & $1.20 \pm 0.41^{\mathrm{a}}$ & $5.78 \pm 0.58^{\mathrm{c}}$ & $5.35 \pm 0.90^{c}$ & $4.50 \pm 0.91^{\mathrm{bc}}$ & $5.66 \pm 0.69^{c}$ \\
\hline & 180 & $5.06 \pm 0.49^{\mathrm{c}}$ & $1.92 \pm 0.08^{\mathrm{ab}}$ & $1.70 \pm 0.80^{\mathrm{a}}$ & $6.38 \pm 0.78^{\mathrm{c}}$ & $4.40 \pm 0.85^{\mathrm{abc}}$ & $5.95 \pm 0.83^{\mathrm{c}}$ & $4.56 \pm 0.53^{\mathrm{bc}}$ \\
\hline & 270 & $6.32 \pm 0.68^{\mathrm{b}}$ & $2.83 \pm 0.43^{\mathrm{a}}$ & $1.58 \pm 0.54^{\mathrm{a}}$ & $7.94 \pm 0.93^{\mathrm{b}}$ & $6.67 \pm 1.08^{\mathrm{b}}$ & $7.20 \pm 1.16^{\mathrm{b}}$ & $7.74 \pm 0.91^{\mathrm{b}}$ \\
\hline
\end{tabular}

${ }^{\mathrm{a}-\mathrm{d}}$ Means in the same row followed by different superscripts differ $(P<0.05)$.

${ }^{1}$ Mean $\pm \mathrm{SE}(\mathrm{n}=4)$ of duplicate determinations in 2 cheese-making experiments. Results are expressed in milligrams per gram of cheese DM. 
Table 3. Concentrations of medium-chain (MC) and long-chain (LC) FFA during ripening and refrigerated storage of ovine milk blue-veined control and high-pressure processed (HPP) cheeses pressurized at 400 or $600 \mathrm{MPa}$ after 3,6 , or 9 wk (W3, W6, W9) of ripening ${ }^{1}$

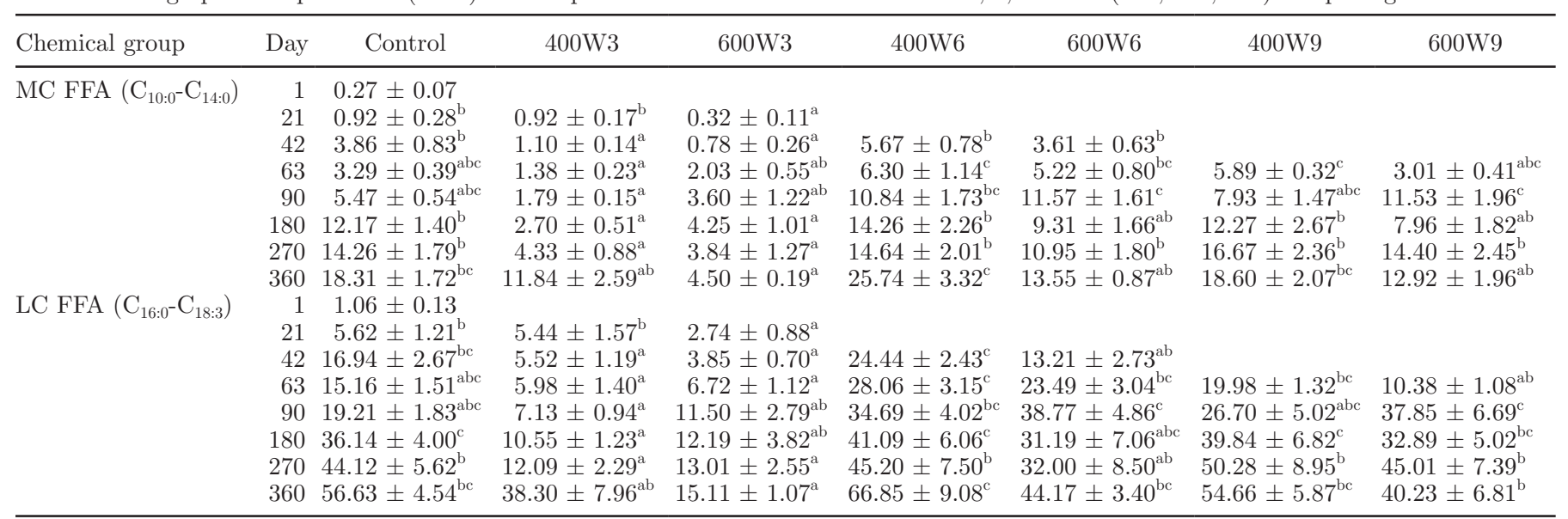

${ }^{\mathrm{a}-\mathrm{c}}$ Means in the same row followed by different superscripts differ $(P<0.05)$.

${ }^{1}$ Mean $\pm \mathrm{SE}(\mathrm{n}=4)$ of duplicate determinations in 2 cheese-making experiments. Results are expressed in milligrams per gram of cheese DM.

Medium-chain ( $\mathbf{M C}, \mathrm{C}_{10: 0}$ to $\mathrm{C}_{14: 0}$ ) FFA are formed through the lipase-mediated hydrolysis of triacylglycerides. Penicillium roqueforti produces 2 extracellular lipases, an acidic lipase and an alkaline lipase that retains activity at $\mathrm{pH} 4.5$ (Lamberet and Menassa, 1983). The formation of MC FFA was significantly $(P<0.001)$ influenced by treatment and cheese age (Table 1$)$. Total MC FFA concentration increased 20.3-fold during ripening of control cheese and 3.3-fold during refrigerated storage (Table 3 ). Individual $\mathrm{MC} \mathrm{FFA} \mathrm{C}_{10: 0}, \mathrm{C}_{12: 0}$, and $\mathrm{C}_{14: 0}$ levels were $2.32,1.17$, and $1.99 \mathrm{mg} / \mathrm{g}$ of DM, respectively, on d 90 and attained $7.89,3.80$, and 6.62 $\mathrm{mg} / \mathrm{g}$ of DM on d 360 .

Long-chain ( $\mathbf{L C}, \mathrm{C}_{16: 0}$ to $\mathrm{C}_{18: 3}$ ) FFA in blue-veined cheeses are mostly derived from triacylglycerides, by the action of $P$. roqueforti lipases. The accumulation of LC FFA in cheese was significantly $(P<0.001)$ influenced by treatment and cheese age (Table 1$)$. Total LC FFA concentration increased 18.1-fold during ripening of control cheese and 2.9-fold during refrigerated storage (Table 3). The major LC FFA in control cheese, $\mathrm{C}_{16: 0}$ and $\mathrm{C}_{18: 1}$, reached levels of 4.31 and $11.14 \mathrm{mg} / \mathrm{g}$ of DM, respectively, on d 90, and 19.43 and $27.03 \mathrm{mg} / \mathrm{g}$ of DM on d 360. As previously recorded for Stilton cheese by Madkor et al. (1987), LC FFA were present at higher concentrations than SC and MC FFA.

Pressurization of cheeses on d 21 limited the formation of SC, MC, and LC FFA (Tables 2 and 3). In contrast, Voigt et al. (2010) did not observe significant differences between the FFA content of pressurized and control blue-veined cheeses. In the present work, the effect was more marked for 600W3 cheese than for $400 \mathrm{~W} 3$ cheese. On d 360, the concentrations of total $\mathrm{SC}, \mathrm{MC}$, and LC FFA in 600W3 cheese were less than half those in 400W3 cheese. Milk lipoprotein lipase was presumably inactivated by milk pasteurization in the present work.

Lactic acid bacteria esterases may withstand cheese pressurization, according to Ávila et al. (2007). To our knowledge, no information on the barotolerance of $P$. roqueforti lipolytic enzymes has been reported. The esterase activity values found in the present work, up to 38.53 pmol of $\alpha$-naphthol per min per gram for control cheese on d 42 (Table 4), were markedly higher than those reported for a non-mold-ripened variety, which ranged from 0.49 to $1.39 \mathrm{pmol}$ of $\alpha$-naphthol per min per gram of cheese (Ávila et al., 2007). The high esterase activity values of blue-veined cheese must be attributed to $P$. roqueforti lipolytic enzymes. These enzymes exhibited a certain baroresistance, according to the data presented in Table 4. Even in the 600W3 cheese, which showed the lowest $(P<0.05)$ esterase activity values throughout ripening and refrigerated storage, esterase activity reached 9.12 pmol of $\alpha$-naphthol per min per gram on d 90 of ripening. Total FFA concentrations in 90 -d cheeses did not correlate significantly with the respective esterase activity values. However, total FFA concentrations in 360-d cheeses correlated significantly $(P<0.05)$ with the respective esterase activity values, and even more strongly $(P<0.01)$ with the esterase activity values obtained for the respective cheeses on $\mathrm{d}$ 90. Levels of significance for the correlations between SC, MC, and LC FFA and esterase activity values equaled those found for total FFA and esterase activity.

Butanoic acid plays an important role in the flavor of many cheese varieties, although at high concentrations (usually in cheeses with the late blowing defect caused by the butyric acid fermentation of lactate by 
Table 4. Esterase activity during ripening and refrigerated storage of ovine milk blue-veined control cheese and high-pressure processed (HPP) cheeses pressurized at 400 or $600 \mathrm{MPa}$ after 3,6 , or $9 \mathrm{wk}$ (W3, W6, W9) of ripening ${ }^{1}$

\begin{tabular}{|c|c|c|c|c|c|c|c|}
\hline Day & Control & 400W3 & $600 \mathrm{~W} 3$ & 400W6 & 600W6 & 400W9 & $600 \mathrm{~W} 9$ \\
\hline 21 & $16.72 \pm 0.40^{\mathrm{c}}$ & $12.62 \pm 0.59^{\mathrm{b}}$ & $4.66 \pm 0.67^{\mathrm{a}}$ & & & & \\
\hline 42 & $38.53 \pm 1.35^{\mathrm{d}}$ & $13.71 \pm 0.80^{\mathrm{b}}$ & $4.98 \pm 0.43^{\mathrm{a}}$ & $28.85 \pm 0.12^{\mathrm{c}}$ & $17.74 \pm 2.21^{\mathrm{b}}$ & & \\
\hline 63 & $23.78 \pm 0.67^{\mathrm{b}}$ & $15.19 \pm 1.05^{\mathrm{ab}}$ & $6.57 \pm 1.05^{\mathrm{a}}$ & $26.80 \pm 2.41^{\mathrm{b}}$ & $15.96 \pm 1.47^{\mathrm{ab}}$ & $13.96 \pm 0.61^{\mathrm{ab}}$ & $10.17 \pm 1.90^{\mathrm{a}}$ \\
\hline 90 & $22.01 \pm 2.47^{\mathrm{bc}}$ & $17.82 \pm 4.02^{\mathrm{abc}}$ & $9.12 \pm 2.30^{\mathrm{a}}$ & $27.36 \pm 3.00^{\mathrm{c}}$ & $12.46 \pm 0.96^{\mathrm{ab}}$ & $19.53 \pm 0.91^{\mathrm{abc}}$ & $16.17 \pm 2.60^{\mathrm{abc}}$ \\
\hline 180 & $33.56 \pm 2.25^{\mathrm{bc}}$ & $12.49 \pm 0.46^{\mathrm{a}}$ & $7.65 \pm 0.36^{\mathrm{a}}$ & $34.47 \pm 4.03^{\mathrm{c}}$ & $28.37 \pm 5.96^{\mathrm{bc}}$ & $19.64 \pm 3.13^{\mathrm{ab}}$ & $10.71 \pm 2.67^{\mathrm{a}}$ \\
\hline 270 & $31.74 \pm 0.33^{\mathrm{d}}$ & $10.89 \pm 1.43^{\mathrm{ab}}$ & $5.52 \pm 0.80^{\mathrm{a}}$ & $32.12 \pm 3.76^{\mathrm{d}}$ & $17.02 \pm 0.72^{\mathrm{bc}}$ & $32.01 \pm 1.48^{\mathrm{d}}$ & $19.75 \pm 0.49^{\mathrm{c}}$ \\
\hline 360 & $28.16 \pm 2.06^{\mathrm{c}}$ & $8.41 \pm 0.43^{\mathrm{ab}}$ & $4.31 \pm 0.22^{\mathrm{a}}$ & $26.18 \pm 0.88^{\mathrm{c}}$ & $5.95 \pm 0.23^{\mathrm{ab}}$ & $11.63 \pm 0.10^{\mathrm{b}}$ & $8.47 \pm 0.71^{\mathrm{ab}}$ \\
\hline
\end{tabular}

${ }^{\mathrm{a}-\mathrm{d}}$ Means in the same row followed by different superscripts differ $(P<0.05)$.

${ }^{1}$ Mean $\pm \mathrm{SE}(\mathrm{n}=4)$ of duplicate determinations in 2 cheese-making experiments. Results are expressed in picomoles of $\alpha$-naphthol per minute and gram of cheese.

clostridia), it becomes undesirable. Hexanoic and octanoic acids are characteristic flavor compounds of aged Grana Padano and Roncal cheeses (Curioni and Bosset, 2002). Medium-chain FFA such as $\mathrm{C}_{10: 0}$ and $\mathrm{C}_{12: 0}$ are key aroma compounds in varieties such as Cheddar, Roncal, and probably others, because of their relatively low perception thresholds. In contrast, LC FFA have high perception thresholds, which limit their contribution to cheese flavor, in spite of the high concentrations commonly reached in many cheese types (Curioni and Bosset, 2002).

\section{Volatile Compounds}

One hundred two compounds were identified in the volatile fraction of ovine milk blue-veined cheese by solid-phase microextraction followed by GC-MS. Lower numbers of volatile compounds have generally been reported for other blue-veined cheeses made exclusively from bovine milk, such as Gorgonzola or Stilton (Moio et al., 2000; Gkatzionis et al., 2009), or including ovine milk in their composition, such as Cabrales and Gamonedo (González de Llano et al., 1990; De Frutos et al., 1991), although 108 volatile compounds were identified or tentatively identified in ovine milk Roquefort cheese (Gallois and Langlois, 1990). The 102 volatile compounds identified in the present work included 5 aldehydes, 12 ketones, 17 alcohols, 12 acids, 35 esters, 9 hydrocarbons, 5 aromatic compounds, 3 nitrogen compounds, 3 terpenes, and 1 sulfur compound. Total concentrations of all groups of volatile compounds were significantly influenced by HPP, but only ketones, acids, esters, and sulfur compounds varied significantly with cheese age during refrigerated storage (Table 1). Out of the 102 individual volatile compounds, 97 were significantly influenced by HPP (86 compounds at $P<$ 0.001 ), whereas 68 varied significantly with cheese age (52 compounds at $P<0.001$ ).

Total aldehydes reached higher levels in control cheese and $400 \mathrm{MPa}$ cheeses than in $600 \mathrm{MPa}$ cheeses on d 180 (Table 5), with acetaldehyde being the main aldehyde at that time. During cheese manufacture and the first days of ripening, acetaldehyde may be formed through the metabolism of lactose, but later it mostly derives from the catabolism of threonine (McSweeney and Sousa, 2000). The population of lactic acid bacteria, which declined on average $0.5 \mathrm{log} \mathrm{cfu} / \mathrm{g}$ in $400 \mathrm{MPa}$ cheeses and $4.2 \mathrm{log} \mathrm{cfu} / \mathrm{g}$ in $600 \mathrm{MPa}$ cheeses immediately after HPP, attained respective mean counts of 8.0, 7.1, and $3.5 \mathrm{log} \mathrm{cfu} / \mathrm{g}$ in control, $400 \mathrm{MPa}$, and 600 MPa cheeses on d 180 (Calzada et al., 2013). The lower acetaldehyde content of $600 \mathrm{MPa}$ cheeses on d 180 may be explained by their low lactic acid bacteria counts and total aerobic counts, which preclude a metabolic activity capable of influencing cheese chemical parameters. Total aldehydes increased in $600 \mathrm{MPa}$ cheeses from $\mathrm{d}$ 180 to 360 due to the formation of 3-methylbutanal (the main aldehyde on d 360), 2-methylbutanal, and 2-methylpropanal from leucine, isoleucine, and valine, respectively, during the last stages of refrigerated storage. The increase in total aldehydes recorded from $\mathrm{d}$ 180 to 360 in $600 \mathrm{MPa}$ cheeses cannot be attributed to microbial metabolism, because of the low counts of lactic acid bacteria, $P$. roqueforti, and other microbial groups in those cheeses. Therefore, abiotic chemical reactions seem the most plausible origin of the branchedchain aldehydes produced from d 180 to 360 in $600 \mathrm{MPa}$ cheeses, which doubled their contents during this period. Aldehydes are key odorants in cheese, with green, sweet, pungent notes for acetaldehyde; green, malty, acrid, pungent notes that turn into pleasant fruity at low concentrations for 3-methylbutanal; malty, nutty notes for 2-methylbutanal; and malty, floral notes for 2-methylpropanal (Curioni and Bosset, 2002).

Total ketones reached their maximum concentration on d 180 in control cheese (Table 5), with 2-pentanone, 2-heptanone, and 2-propanone as the major ketones. Penicillium roqueforti is a main producer of methyl ketones via the $\beta$-oxidation and decarboxylation of FFA, with enhanced production by germinating spores 
Table 5. Levels of total volatile aldehydes, ketones, alcohols, acids, and esters during refrigerated storage of ovine milk blue-veined control and high-pressure processed (HPP) cheeses pressurized at 400 or $600 \mathrm{MPa}$ after 3, 6, or 9 wk (W3, W6, W9) of ripening ${ }^{1}$

\begin{tabular}{|c|c|c|c|c|c|c|c|c|}
\hline Volatile group & Day & Control cheese & 400W3 & $600 \mathrm{~W} 3$ & 400W6 & $600 \mathrm{~W} 6$ & 400W9 & 600W9 \\
\hline Aldehydes & 360 & $10.64 \pm 0.88^{\mathrm{a}}$ & $10.58 \pm 0.66^{\mathrm{a}}$ & $8.88 \pm 1.14^{\mathrm{a}}$ & $7.06 \pm 0.78^{\mathrm{a}}$ & $11.74 \pm 1.74^{\mathrm{a}}$ & $9.57 \pm 0.72^{\mathrm{a}}$ & $11.35 \pm 0.79^{\mathrm{a}}$ \\
\hline \multirow[t]{2}{*}{ Alcohols } & 180 & $1,452 \pm 105^{\mathrm{d}}$ & $806 \pm 21^{b c}$ & $209 \pm 9^{\mathrm{a}}$ & $1,070 \pm 21^{\mathrm{c}}$ & $512 \pm 74^{\mathrm{ab}}$ & $881 \pm 95^{\mathrm{bc}}$ & $332 \pm 28^{\mathrm{a}}$ \\
\hline & 360 & $1,496 \pm 83^{\mathrm{c}}$ & $744 \pm 54^{\mathrm{b}}$ & $239 \pm 7^{\mathrm{a}}$ & $1,281 \pm 115^{\mathrm{c}}$ & $481 \pm 26^{\mathrm{ab}}$ & $775 \pm 46^{\mathrm{b}}$ & $242 \pm 13^{\mathrm{a}}$ \\
\hline Acids & 180 & $2,465 \pm 107^{\mathrm{b}}$ & $1,517 \pm 144^{\mathrm{a}}$ & $1,441 \pm 211^{\mathrm{a}}$ & $2,631 \pm 55^{\mathrm{b}}$ & $2,506 \pm 88^{\mathrm{b}}$ & $2,804 \pm 123^{\mathrm{b}}$ & $2,844 \pm 88^{\mathrm{b}}$ \\
\hline Esters & 360 & $1,493 \pm 167^{\mathrm{c}}$ & $420 \pm 36^{\mathrm{ab}}$ & $61.2 \pm 4.8^{\mathrm{a}}$ & $760 \pm 55^{\mathrm{b}}$ & $311 \pm 30^{\mathrm{ab}}$ & $841 \pm 24^{\mathrm{b}}$ & $173 \pm 15^{\mathrm{a}}$ \\
\hline
\end{tabular}

\footnotetext{
${ }^{\mathrm{a}-\mathrm{d}}$ Means in the same row followed by different superscripts differ $(P<0.05)$.

${ }^{1}$ Mean $\pm \mathrm{SE}(\mathrm{n}=4)$ of duplicate determinations in 2 cheese-making experiments. Results are expressed as relative abundances with respect to the internal standard.
}

(Kinsella and Hwang, 1976). On d 180, P. roqueforti counts reached $7.1 \mathrm{log} \mathrm{cfu} / \mathrm{g}$ in control cheese and 5.4 $\log \mathrm{cfu} / \mathrm{g}$ on average in $400 \mathrm{MPa}$ cheeses, whereas $P$. roqueforti counts were below the detection level in 600 MPa cheeses (Calzada et al., 2013). These differences in $P$. roqueforti counts may help to explain the higher ketone content in control cheese than in HPP cheeses on d 180. Reduced formation of ketones during the refrigerated storage of pressurized blue-veined cheeses compared with control cheese has been reported by Voigt et al. (2010). In the present work, the formation of methyl ketones in $600 \mathrm{MPa}$ cheeses, with $P$. roqueforti counts below detection level following HPP treatments, needs further explanation. Either sublethally injured $P$. roqueforti cells unable to grow on selective media carried out the chemical reactions responsible for methyl ketone formation or these reactions took place abiotically in the absence of viable $P$. roqueforti cells. From d 180 to 360 , we observed marked increases in the ketone content of $400 \mathrm{MPa}$ cheeses, whereas ketones remained stable in control cheese. Methyl ketones are the characteristic flavor compounds of blue-veined cheeses, in particular, 2-heptanone, which has a blue cheese note and a low perception threshold, but also 2-pentanone, with a sweet fruity odor note, and 2-propanone, with hay and wood pulp odor notes (Molimard and Spinnler, 1996).

Total alcohols were at higher levels in control cheese and $400 \mathrm{MPa}$ cheeses than in $600 \mathrm{MPa}$ cheeses on $\mathrm{d}$ 180 (Table 5). The main alcohols at d 180 were 2-pentanol, 2-propanol, and ethanol, followed by 1-butanol, 2-heptanol, and 3-methyl-1-butanol. The formation of 2-alkanols through the reduction of the corresponding 2-alkanones by both spores and mycelium of $P$. roqueforti has been suggested as a cellular detoxifying mechanism (Kinsella and Hwang, 1976). The lowest content of 2 -alkanols was found in $600 \mathrm{~W} 3$ cheese, in which $P$. roqueforti had the shortest period to exert its metabolic activity before being inactivated by HPP. The formation of other alcohols is independent from the metabolic activity of $P$. roqueforti. Branched-chain 3 -methyl-1-butanol is produced through the reduction of the respective aldehyde, derived from leucine (Yvon and Rijnen, 2001). Ethanol is considered to be mostly produced in cheese through the fermentation of lactose by lactic acid bacteria (Fox and Wallace, 1997). However, its content doubled in control cheese from d 180 to 360 , a stage at which lactose, glucose, and galactose were certainly exhausted, whereas ethanol content did not vary in HPP cheeses. Reduction of acetaldehyde seems a plausible source of ethanol during the refrigerated storage of control cheese. Reduction of 1-butanal may be also the origin of 1-butanol, which increased from d 180 to 360 in control cheese but not in HPP cheeses. Primary alcohols show green, alcoholic notes, and secondary alcohols have fruity, herbaceous notes, whereas 3-methyl-1-butanol has pleasant, fresh cheese notes (Curioni and Bosset, 2002). They all contribute to cheese flavor, directly and as substrates for ester formation.

Total volatile acids attained lower levels on d 180 in 400W3 and 600W3 cheeses (Table 5). The main acids on d 180 as determined by GC-MS were butanoic, hexanoic, and acetic acids, which accounted for 54, 29, and $12 \%$, respectively, of total acids in cheeses, on average. Total acids increased in all cheeses from d 180 to 360 , more so in control cheese and $400 \mathrm{MPa}$ cheeses than in $600 \mathrm{MPa}$ cheeses, in spite of their contribution to ester formation, with significant increases of all the individual acids. Because acids are formed through microbial metabolism and lipolysis, these results indicate that both phenomena probably remained active even after HPP of cheese at the higher pressure level.

Total esters were negatively affected by HPP, in particular at $600 \mathrm{MPa}$, with $600 \mathrm{~W} 3$ cheese showing the lowest ester contents on d 180 and 360, and control 
cheese the highest contents (Table 5). Ethyl butanoate, methyl hexanoate, and ethyl hexanoate were the major esters on d 180, followed by methyl butanoate, ethyl octanoate, and methyl octanoate. On d 360, ethyl butanoate, ethyl hexanoate, and methyl hexanoate were predominant, followed by ethyl octanoate, methyl butyrate, and ethyl acetate. Esters may be formed in cheese by esterification, from alcohols and carboxylic acids, or by alcoholysis, a transferase reaction in which fatty acyl groups from acylglycerols and acyl-CoA derivatives are directly transferred to alcohols, the second mechanism being the major one in lactic acid bacteria and yeasts (Liu et al., 2004). To our knowledge, the existence of alcohol acyltransferases in Penicillium spp. has not been reported. It may be hypothesized that ester formation in control and $400 \mathrm{MPa}$ cheeses took place by both mechanisms, whereas in $600 \mathrm{MPa}$ cheeses, with a negligible microbial population, the first mechanism would predominate. Esters generally show sweet, fruity, and floral notes, have a low perception threshold, and are key odorants in many cheeses. At low concentrations, esters contribute positively to the overall flavor balance in cheese, by themselves and by masking the effect of unclean off-flavors with pungent, sharp, cowy, and barny notes. At higher concentrations, a fruity flavor defect may arise (Curioni and Bosset, 2002; Liu et al., 2004). Two cyclic esters, $\gamma$-butyrolactone and $\gamma$-caprolactone, were detected at low levels and increased moderately from d 180 to 360 . Their highest contents were found in control and 400 $\mathrm{MPa}$ cheeses. Lactones are considered to be generated by the hydrolysis of hydroxy-fatty acid triglycerides followed by lactonization (Jolly and Kosikowski, 1975). They generally have pronounced fruity flavor notes and a low perception threshold, and may be of importance to the aroma of some cheese varieties such as Bleu d'Auvergne (Gallois and Langlois, 1990). However, pungent, fetid, buttery notes have been assigned to $\gamma$-butyrolactone (Molimard and Spinnler, 1996).

Total hydrocarbons tended to reach higher levels in control cheese than in HPP cheeses, although the differences were significant $(P<0.05)$ only for $600 \mathrm{~W} 3$, 400W9, and 600W9 cheeses on d 180 and for 600W9 cheeses on d 360 (Table 6). We observed no significant increase in the hydrocarbon content during refrigerated storage of cheeses from d 180 to 360 . The main hydrocarbons found - octane, hexane, and pentamethylheptane - have solvent, gasoline-like odor notes. The presence of hydrocarbons, generally derived from lipid oxidation (Carbonell et al., 2002; Collins et al., 2003), has been reported in ovine milk cheeses such as La Serena and Manchego (Carbonell et al., 2002; FernándezGarcía et al., 2002) but not in Roquefort, Gorgonzola, or Stilton blue-veined cheeses (Gallois and Langlois, 1990; Moio et al., 2000; Gkatzionis et al., 2009).

Total aromatic compounds were generally at lower levels in 400W3 and 600W3 cheeses than in the others (Table 6). Early HPP treatment, on d 21, which severely impaired growth and metabolism of $P$. roqueforti (Calzada et al., 2013), was more crucial than the pressure level applied. The main aromatic compounds found were toluene and 1-methoxy-4-methylbenzene, which did not vary significantly from d 180 to 360; phenol, which declined; and 4-methyl-phenol, which increased. Aromatic compounds may be formed in cheese through the microbial catabolism of aromatic amino acids (Yvon and Rijnen, 2001). Toluene and phenol have been detected in the volatile fraction of cheeses made from ovine raw milk (Carbonell et al., 2002; Fernández-García et al., 2004), but not in blueveined cheeses (Gallois and Langlois, 1990; Lawlor et al., 2003).

Total nitrogen compounds were significantly influenced by HPP and did not vary with cheese age from

Table 6. Levels of total volatile hydrocarbons, aromatic compounds, terpenes, nitrogen compounds, and sulfur compounds during refrigerated storage of ovine milk blue-veined control and high-pressure processed (HPP) cheeses pressurized at 400 or $600 \mathrm{MPa}$ after 3, 6, or 9 wk (W3, W6, W9) of ripening ${ }^{1}$

\begin{tabular}{|c|c|c|c|c|c|c|c|c|}
\hline Volatile group & Day & Control & 400W3 & $600 \mathrm{~W} 3$ & 400W6 & $600 \mathrm{~W} 6$ & 400W9 & 600W9 \\
\hline Aromatic compounds & $\begin{array}{l}360 \\
180\end{array}$ & $\begin{array}{r}9.86 \pm 1.27^{\mathrm{D}} \\
17.37 \pm 1.61^{\mathrm{c}}\end{array}$ & $\begin{array}{l}8.14 \pm 0.73^{\text {ab }} \\
8.86 \pm 0.29^{\text {ab }}\end{array}$ & $\begin{array}{l}6.27 \pm 0.57^{\mathrm{ab}} \\
5.71 \pm 0.63^{\mathrm{a}}\end{array}$ & $\begin{aligned} 6.93 & \pm 0.70^{\mathrm{ab}} \\
14.44 & \pm 0.91^{\mathrm{bc}}\end{aligned}$ & $\begin{aligned} 6.87 & \pm 0.79^{\mathrm{ab}} \\
13.67 & +0.88^{\mathrm{bc}}\end{aligned}$ & $\begin{aligned} 6.00 & \pm 0.45^{\mathrm{ab}} \\
10.42 & \pm 0.13^{\mathrm{ab}}\end{aligned}$ & $\begin{aligned} 4.56 & \pm 0.28^{\mathrm{a}} \\
14.03 & \pm 0.68^{\mathrm{bc}}\end{aligned}$ \\
\hline \multirow[t]{2}{*}{ Nitrogen compounds } & 180 & $3.37 \pm 0.17^{\mathrm{ab}}$ & $2.26 \pm 0.28^{\mathrm{a}}$ & $3.14 \pm 0.38^{\mathrm{ab}}$ & $3.91 \pm 0.27^{\mathrm{b}}$ & $3.67 \pm 0.28^{\mathrm{b}}$ & $3.78 \pm 0.31^{\mathrm{b}}$ & $3.46 \pm 0.41^{\mathrm{ab}}$ \\
\hline & 360 & $5.40 \pm 0.60^{\mathrm{b}}$ & $2.89 \pm 0.45^{\mathrm{a}}$ & $2.41 \pm 0.20^{\mathrm{a}}$ & $4.06 \pm 0.40^{\mathrm{ab}}$ & $3.34 \pm 0.40^{\mathrm{ab}}$ & $4.38 \pm 0.69^{\mathrm{ab}}$ & $3.29 \pm 0.34^{\mathrm{ab}}$ \\
\hline Terpenes & 180 & $1.50 \pm 0.10^{\mathrm{b}}$ & $1.12 \pm 0.08^{\mathrm{ab}}$ & $0.89 \pm 0.02^{\mathrm{a}}$ & $1.72 \pm 0.22^{\mathrm{b}}$ & $1.64 \pm 0.13^{\mathrm{b}}$ & $1.43 \pm 0.16^{\mathrm{ab}}$ & $1.47 \pm 0.13^{\mathrm{ab}}$ \\
\hline Sulfur compounds & 360 & $1.18 \pm 0.12^{\mathrm{a}}$ & $0.94 \pm 0.10^{\mathrm{a}}$ & $0.92 \pm 0.07^{\mathrm{a}}$ & $1.22 \pm 0.13^{\mathrm{a}}$ & $1.04 \pm 0.12^{\mathrm{a}}$ & $1.18 \pm 0.10^{\mathrm{a}}$ & $1.05 \pm 0.10^{\mathrm{a}}$ \\
\hline
\end{tabular}

\footnotetext{
${ }^{\mathrm{a}-\mathrm{c}}$ Means in the same row followed by different superscripts differ $(P<0.05)$.

${ }^{1}$ Mean $\pm \mathrm{SE}(\mathrm{n}=4)$ of duplicate determinations in 2 cheese-making experiments. Results are expressed as relative abundances with respect to the internal standard.
} 
d 180 to 360 (Tables 1 and 6). Methanamide, butyramide, and 2,6-dimethylpyrazine, the nitrogen compounds detected in the present work, were at low levels in all cheeses (data not shown). The concentrations of butyramide and 2,6-dimethylpyrazine more than doubled in control cheese from d 180 to 360, whereas they remained largely constant in HPP cheeses during this period. The increases of these compounds in control cheese might be associated with the metabolism of cheese microbiota, but their origin could not be traced to a particular microbial group.

Total terpenes attained lower levels in 400W3 and 600W3 cheeses than in the other cheeses (Table 6). Terpenes are secondary plant metabolites, whose presence in an ovine milk cheese not ripened by molds has been traced to the feed (Fernández-García et al., 2008). Additionally, $P$. roqueforti strains cultivated on synthetic media have been reported to produce terpenes (Chalier and Crouzet, 1993). Pressurization of cheeses on d 21, which impeded normal growth of $P$. roqueforti (Calzada et al., 2013), likely hindered terpene synthesis during ripening and refrigerated storage of $400 \mathrm{~W} 3$ and 600W3 cheeses. Terpenes found in the present work were endoborneol and 2 unidentified sesquiterpenes, all common volatile compounds in ovine milk cheeses (Carbonell et al., 2002) but not in blue-veined cheeses (Lawlor et al., 2003). In contrast to our results, the latter authors reported the presence of $\alpha$-pinene and limonene in the 6 blue-veined varieties they investigated. Terpenes confer herbaceous, floral, and fruity odor notes, and may be useful as geographical markers of cheese origin (Bugaud et al., 2001).

Dimethylsulfone, the only sulfur compound detected in blue-veined ovine milk cheese, varied with HPP and cheese age (Tables 1 and 6). Dimethylsulfone has been detected in Cheddar cheese at levels that doubled from medium-age to extra sharp cheese (Burbank and Qian, 2005). It can be formed through the oxidation of dimethylsulfide (Al-Attabi et al., 2009) or may derive directly from the pasture, because it is present in cruciferous and bulbaceous plants. More common sulfur compounds such as dimethylsulfide or dimethyldisulfide (formed through the degradation of methionine), which have been reported in other blue-veined cheese varieties (Gallois and Langlois, 1990; Lawlor et al., 2003), were not found in HPP or control cheeses in the current study.

The sensory characteristics of control cheeses and HPP cheeses except the 600W3 cheese showed negligible variations during the refrigerated storage period, according to the results obtained in a previous work (Calzada et al., 2013). In contrast, the flavor quality of the 600W3 cheese declined during refrigerated storage, which can be attributed to the lower contents of some groups of flavor compounds, which might be unsatisfactorily balanced from a sensory point of view.

\section{Principal Component Analysis}

Principal component analysis was carried out on the total concentrations of the 4 groups of carboxylic acids (acetic + propionic, SC FFA, MC FFA, and LC FFA) determined by GC and the total levels of the 10 groups of volatile compounds (aldehydes, ketones, alcohols, acids, esters, hydrocarbons, aromatic compounds, nitrogen compounds, terpenes, and sulfur compounds) determined by GC-MS. Two functions explained each over $10 \%$ of the variance. Function 1, formed by the 4 groups of carboxylic acids and 8 groups of volatile compounds (excluding aldehydes and hydrocarbons), explained $50.6 \%$ of the variance, whereas function 2 , formed by aldehydes and hydrocarbons, explained $15.7 \%$ of the variance. Function 1 was associated with cheese age, and function 2 with absence of (control) or milder (400 MPa) HPP treatment. When cheeses were plotted against functions 1 and 2 (Figure 1), function 1 correctly separated all the 360-d cheeses, located in the positive semi-plane, from all the 180-d cheeses, located in the negative semi-plane, with the only exception being the 360-d 600W3 cheese, which was located in the negative semi-plane. The decelerating effect of early HPP (d 21) at the higher pressure level (600 MPa) on the biochemical changes occurring during cheese ripening and refrigerated storage was thus highlighted. The contents of FFA and volatile compounds in the 360-d $600 \mathrm{~W} 3$ cheese were closer to those of $180-\mathrm{d}$ cheeses than to the contents of $360-\mathrm{d}$ cheeses.

\section{CONCLUSIONS}

High-pressure processing influenced the total concentrations of all groups of carboxylic acids and volatile compounds found in ovine milk blue-veined cheese. The greatest reduction in the concentrations of carboxylic acids during ripening and refrigerated storage was recorded for the cheese pressurized at $600 \mathrm{MPa}$ on d 21, which showed the lowest esterase activity values. Control cheese was richest in alcohols, esters, and aromatic compounds, whereas cheese pressurized at $600 \mathrm{MPa}$ on d 21 showed the lowest contents of aldehydes, ketones, alcohols, acids, esters, aromatic compounds, and terpenes. The reduced levels of flavor compounds in the 600W3 cheese, which were associated with low counts of $P$. roqueforti and other microbial groups, resulted in lower flavor quality scores during refrigerated storage. The high concentrations of carboxylic acids and volatile compounds in control cheese and the other HPP cheeses did not impair their sensory characteristics, probably 


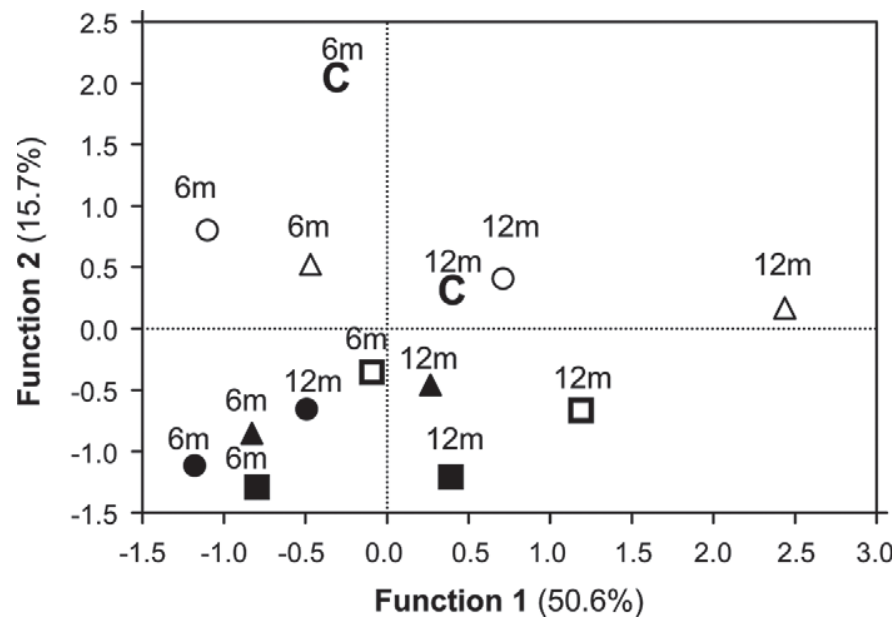

Figure 1. Distribution of control and high-pressure processed (HPP) blue-veined cheeses pressurized at 400 or $600 \mathrm{MPa}$ on d 21, 42 , or 63 after manufacture (W3, W6, W9) on the plane defined by functions 1 and 2 of the principal component analysis. Each symbol represents the averaged value of the 2 batches of cheese. Treatments are as follows: $\mathrm{C}=$ control; $\mathrm{O}=400 \mathrm{~W} 3 ; \boldsymbol{\bullet}=600 \mathrm{~W} 3 ; \Delta=400 \mathrm{~W} 6$; $\boldsymbol{\Delta}$ $=600 \mathrm{~W} 6 ; \square=400 \mathrm{~W} 9 ; \mathbf{\square}=600 \mathrm{~W} 9$. Cheese age is as follows: $180 \mathrm{~d}=$ $6 \mathrm{mo} ; 360 \mathrm{~d}=12 \mathrm{mo}$.

because an adequate balance of flavor compounds was maintained during refrigerated storage.

\section{ACKNOWLEDGMENTS}

This research was funded by AGL 2009-07801 project from the Ministry of Science and Innovation (MICINN, Spain). J. Calzada is the recipient of a FPI grant (MICINN, Spain). The authors thank the valuable help of V. Carbonero (Lácteas Toledo, Guadamur, Spain) with cheese supply and of F. Purroy (NC Hyperbaric, Burgos, Spain) with high pressure treatments.

\section{REFERENCES}

Al-Attabi, Z., B. R. D'Arcy, and H. C. Deeth. 2009. Volatile sulphur compounds in UHT milk. Crit. Rev. Food Sci. Nutr. 49:28-47.

Arqués, J. L., S. Garde, E. Fernández-García, P. Gaya, and M. Nuñez. 2007. Volatile compounds, odor, and aroma of La Serena cheese high-pressure treated at two different stages of ripening. J. Dairy Sci. 90:3627-3639.

Arqués, J. L., S. Garde, P. Gaya, M. Medina, and M. Nuñez. 2006. Inactivation of microbial contaminants in raw milk La Serena cheese by high-pressure treatments. J. Dairy Sci. 89:888-891.

Ávila, M., J. Calzada, S. Garde, and M. Nuñez. 2007. Effect of a bacteriocin-producing Lactococcus lactis strain and high-pressure treatment on the esterase activity and free fatty acids in Hispánico cheese. Int. Dairy J. 17:1415-1423.

Ávila, M., S. Garde, E. Fernández-García, M. Medina, and M. Nuñez. 2006. Effect of high-pressure treatment and a bacteriocin-producing lactic culture on the odor and aroma of Hispánico cheese: Correlation of volatile compounds and sensory analysis. J. Agric. Food Chem. 54:382-389.

Bugaud, C., S. Buchin, J. B. Coulon, A. Hauwuy, and D. Dupont. 2001. Influence of the nature of alpine pastures on plasmin activ- ity, fatty acid and volatile compound composition of milk. Lait 81:401-414.

Burbank, H. M., and M. C. Qian. 2005. Volatile sulfur compounds in Cheddar cheese determined by headspace solid-phase microextraction and gas chromatograph-pulsed flame photometric detection. J. Chromatogr. A 1066:149-157.

Calzada, J., A. del Olmo, A. Picon, P. Gaya, and M. Nuñez. 2013. Proteolysis and biogenic amine buildup in high-pressure treated ovine milk blue-veined cheese. J. Dairy Sci. 96:4816-4829.

Carbonell, M., M. Nuñez, and E. Fernández-García. 2002. Evolution of the volatile components of ewe raw milk La Serena cheese during ripening. Correlation with flavor characteristics. Lait 82:683-698.

Chalier, P., and J. Crouzet. 1993. Production of volatile components by Penicillium roqueforti cultivated in the presence of soya bean oil. Flavour Frag. J. 8:43-49.

Collins, Y. F., P. L. H. McSweeney, and M. G. Wilkinson. 2003. Lipolysis and free fatty acid catabolism in cheese: A review of current knowledge. Int. Dairy J. 13:841-866.

Curioni, P. M. G., and J. O. Bosset. 2002. Key odorants in various cheese types as determined by gas chromatography-olfactometry. Int. Dairy J. 12:959-984.

De Frutos, M., J. Sanz, and I. Martinez-Castro. 1991. Characterization of artisanal cheeses by GC and GC/MS analysis of their medium volatility (SDE) fraction. J. Agric. Food Chem. 39:524-530.

Fernández-García, E., M. Carbonell, J. Calzada, and M. Nuñez. 2006. Seasonal variation of the free fatty acids contents of Spanish ovine milk cheeses protected by a designation of origin: A comparative study. Int. Dairy J. 16:252-261.

Fernández-García, E., M. Carbonell, P. Gaya, and M. Nuñez. 2004 Evolution of the volatile components of ewes raw milk Zamorano cheese. Seasonal variation. Int. Dairy J. 14:701-711.

Fernández-García, E., M. Carbonell, and M. Nuñez. 2002. Volatile fraction and sensory characteristics of Manchego cheese. 1. Comparison of raw and pasteurized milk cheese. J. Dairy Res. 69:579 593.

Fernández-García, E., M. Imhof, H. Schlichtherle-Cerny, J. O. Bosset, and M. Nuñez. 2008. Terpenoids and benzenoids in La Serena cheese made at different seasons of the year with a Cynara cardunculus extract as coagulant. Int. Dairy J. 18:147-157.

Fox, P. F., and J. M. Wallace. 1997. Formation of flavor compounds in cheese. Adv. Appl. Microbiol. 45:17-85.

Gallois, A., and D. Langlois. 1990. New results in the volatile odorous compounds of French cheeses. Lait 70:89-106.

García-Risco, M. R., I. Recio, E. Molina, and R. López-Fandiño. 2003. Plasmin activity in pressurized milk. J. Dairy Sci. 86:728-734.

Gkatzionis, K., R. S. T. Linforth, and C. E. R. Dodd. 2009. Volatile profile of Stilton cheeses: Differences between zones within a cheese and dairies. Food Chem. 113:506-512.

González de Llano, D., M. Ramos, C. Polo, J. Sanz, and I. MartinezCastro. 1990. Evolution of the volatile components of an artisanal blue cheese during ripening. J. Dairy Sci. 73:1676-1683.

Gripon, J.-C., M. J. Desmazeaud, D. Le Bars, and J. L. Bergère. 1977. Role of proteolytic enzymes of Streptococcus lactis, Penicillium roqueforti, and Penicillium caseicolum during cheese ripening. J. Dairy Sci. 60:1532-1538.

Huppertz, T., P. F. Fox, and A. L. Kelly. 2004. Susceptibility of plasmin and chymosin in Cheddar cheese to inactivation by high pressure. J. Dairy Res. 71:496-499.

Jolly, R. C., and F. V. Kosikowski. 1975. Quantification of lactones in ripening pasteurized milk blue cheese containing added microbial lipases. J. Agric. Food Chem. 23:1175-1176.

Juan, B., V. Ferragut, M. Buffa, B. Guamis, and A. Trujillo. 2007. Effects of high pressure on proteolytic enzymes in cheese: Relationship with the proteolysis of ewe milk cheese. J. Dairy Sci. 90:2113-2125.

Kinsella, J. E., and D. Hwang. 1976. Biosynthesis of flavors by Penicillium roqueforti. Biotechnol. Bioeng. 18:927-938.

Lamberet, G., and A. Menassa. 1983. Purification and properties of an acid lipase from Penicillium roqueforti. J. Dairy Res. 50:459-468.

Lawlor, J. B., C. M. Delahunty, J. Sheehan, and M. G. Wilkinson. 2003. Relationships between sensory attributes and the volatile 
compounds, non-volatile and gross compositional constituents of six blue-type cheese. Int. Dairy J. 13:481-494.

Liu, S.-Q., R. Holland, and V. L. Crow. 2004. Esters and their biosynthesis in fermented dairy products: A review. Int. Dairy J. 14:923-945.

Madkor, S., P. F. Fox, S. I. Shalabi, and N. H. Metwalli. 1987. Studies on the ripening of Stilton cheese: Lipolysis. Food Chem. 25:93109.

Mallia, S., E. Fernández-García, and J. O. Bosset. 2005. Comparison of purge and trap and solid phase microextraction techniques for studying the volatile aroma compounds of three European PDO hard cheeses. Int. Dairy J. 15:741-758.

Malone, A. S., C. Wick, T. H. Shellhammer, and P. D. Courtney. 2003. High pressure effects on proteolytic and glycolytic enzymes involved in cheese manufacturing. J. Dairy Sci. 86:1139-1146.

McSweeney, P. L. H., and M. J. Sousa. 2000. Biochemical pathways for the production of flavour compounds in cheese during ripening: A review. Lait 80:293-324.

Moio, L., L. Piombino, and F. Addeo. 2000. Odour-impact compounds of Gorgonzola cheese. J. Dairy Res. 67:273-285.

Molimard, P., and H. E. Spinnler. 1996. Compounds involved in the flavour of surface mold-ripened cheeses: Origins and properties. J. Dairy Sci. 79:169-184.

Morales, P., E. Fernández-García, and M. Nuñez. 2005. Volatile compounds produced in cheese by Pseudomonas strains of dairy origin belonging to six different species. J. Agric. Food Chem. 53:68356843.

O'Reilly, C. E., P. M. O'Connor, A. L. Kelly, T. P. Beresford, and P. M. Murphy. 2000. Use of hydrostatic pressure for inactivation of microbial contaminants in cheese. Appl. Environ. Microbiol. 66:4890-4896.

Tejada, L., R. Gómez, M. Vioque, E. Sánchez, C. Mata, and J. Fernández-Salguero. 2000. Effect of freezing and frozen storage on the sensorial characteristics of Los Pedroches, a Spanish ewe milk cheese. J. Sens. Stud. 15:251-262.

Van Hekken. D. L., M. H. Tunick, and Y. W. Park. 2005. Effect of frozen storage on the proteolytic and rheological properties of soft caprine milk cheese. J. Dairy Sci. 88:1966-1972.

Voigt, D. D., F. Chevalier, M. C. Qian, and A. L. Kelly. 2010. Effect of high-pressure treatment on microbiology, proteolysis, lipolysis and levels of flavor compounds in mature blue-veined cheese. Innov. Food Sci. Emerg. Technol. 11:68-77.

Wick, C., U. Nienaber, O. Anggraeni, T. H. Shellhammer, and P. D Courtney. 2004. Texture, proteolysis and viable lactic acid bacteria in commercial Cheddar cheeses treated with high pressure. J. Dairy Res. 71:107-115.

Yvon, M., and L. Rijnen. 2001. Cheese flavour formation by amino acid catabolism. Int. Dairy J. 11:185-201. 